\title{
Identificação de marcas moleculares associadas à ausência de sementes em videira
}

\author{
Identification of molecular markers associated to the absence of seeds in grapevine
}

\section{Ana Veruska Cruz da Silva ${ }^{1}$ Antonio Baldo Geraldo Martins ${ }^{2}$}

\section{RESUMO}

A ausência de sementes tem sido uma característica bastante exigida pelos consumidores de uvas de mesa. O objetivo deste trabalho foi identificar marcas moleculares associadas à ausência de sementes, utilizando as técnicas RAPD e fAFLP. Foram utilizadas folhas jovens de 19 cultivares. $\mathrm{Na}$ análise RAPD 30, iniciadores possibilitaram amplificação de todas as amostras, produzindo 392 bandas polimórficas. Foi possível encontrar uma marca específica para a ausência de sementes, utilizando o iniciador UBC 443, que poderá futuramente ser utilizado para o desenvolvimento de marcadores SCAR, possibilitando a criação de um teste de identificação rápida e precoce de apirenia em videira. A análise fAFLP proporcionou a visualização de um dendrograma com grupos específicos de cultivares com sementes, sem sementes $e$ porta enxertos.

Palavras-chave: Vitis, RAPD, fAFLP, apirenia.

\section{ABSTRACT}

Seedless has been an important characteristic of table grapes required by consumers. The objective was to identify molecular markers associated to seedless, by RAPD and fAFLP techniques with young leaves samples of 19 cultivars. Thirty primers were used for RAPD analysis, producing a total of 337 polymorphic bands. It was also to find a specific mark for seedless, using UBC 443 primer. This mark would be transformed in a scar marker, making possible the early identification of seedless grape possible. The fAFLP analysis provided a visualization of a dendrogram with specific groups, separated in three different cultivars: with seeds, without seeds and the rootstocks.

Key words: Vitis, RAPD, fAFLP, seedless.

\section{INTRODUÇÃO}

Atualmente, a criação de cultivares de uvas de mesa sem sementes é uma das grandes prioridades dos programas de melhoramento da videira em todo o mundo. Esse fato tem restringido bastante a exportação brasileira, já que os produtores, por não disporem de cultivares adaptadas, têm perdido boas oportunidades de inserção no mercado internacional.

É freqüente o surgimento de dúvidas acerca dos genótipos de videira no campo. Tradicionalmente, os métodos utilizados para identificação e para estimar as relações filogenéticas existentes entre eles são baseados em estudos morfológicos, o que, no caso da viticultura, é chamado de ampelografia (GALET, 1979).

Embora muito cultivada e de grande importância econômica mundial, ainda há muito que se pesquisar sobre a genética da videira. Existem alguns questionamentos sobre a real existência de algumas espécies de videira, devido à ocorrência de vários cruzamentos interespecíficos, resultando em híbridos vigorosos e férteis $F_{1}$ (HANCOCK, 1992). Esta situação cria problemas desde a documentação e preservação de bancos de germoplasma ao cultivo e utilização dessas espécies.

O uso de marcadores moleculares de DNA para detectar polimorfismos entre cultivares de uva foi demonstrado por STRIEM et al. (1990), que foram os pioneiros na procura de marcas moleculares ligadas à apirenia, que é a ausência de sementes. A análise genética para detectar polimorfismos, através da técnica da reação em cadeia da DNA polimerase (PCR), revelou a possibilidade do uso desta metodologia para a identificação de várias marcas moleculares correlacionadas a essa "ausência de sementes", o que contribuiria para a pré-seleção de plantas cujos frutos não produzissem sementes (GRAY \& MEREDITH, 1992).

${ }^{1}$ Departamento de Engenharia Agronômica, Universidade Federal de Sergipe (UFS), Av. Marechal Rondon, s/n. Jardim Rosa Elze, 49100-000, São Cristóvão, SE, Brasil. E-mail: anaveruska@ufs.br. Autor para correspondência.

${ }^{2}$ Departamento de Produção Vegetal, Universidade Estadual Paulista (UNESP), Campus de Jaboticabal, Jaboticabal, São Paulo, Brasil. 
A análise de fAFLP (Polimorfismo de comprimento de fragmentos amplificados por fluorescência) representa uma técnica mais recente. Uma de suas principais vantagens é a utilização de uma pequena quantidade de DNA, além da possibilidade de amplos estudos de um genoma (SCOTT et al., 2000), uma vez que se obtém um grande número de fragmentos que são gerados e resolvidos em um único gel.

A eficiência da técnica fAFLP foi testada por REGNER et al., (2000) para caracterização de cultivares e clones de Vitis vinifera ('Gruner Veltliner', 'Chardonnay' e 'Pinot Blanc'). Além da identificação de 220 cultivares e da relação existente entre eles, os autores ainda propuseram uma definição sobre suas origens.

Comparando os métodos RAPD (Polimorfismo de DNA amplificado ao acaso) e fAFLP para identificação genética de videira, NARVÁEZ et al. (2000) obtiveram alta reprodutibilidade, sendo que os dois métodos permitiram diferenciar todas as cultivares analisadas. Os autores propuseram que o fAFLP seria uma melhor alternativa para diferenciar clones, devido à sua maior reprodutibilidade e à maior quantidade de informações por reação, em relação ao RAPD.

Diferentes acessos de várias coleções de videiras existentes na Espanha foram analisados por fAFLP. Testando 12 combinações de iniciadores (FAM/ NED/JOE), obteve-se 400 bandas polimórficas. Entretanto, em alguns casos, apenas uma combinação de iniciadores pode resultar numa quantidade suficiente para a realização das análises, dependendo do objetivo da pesquisa, o que, na verdade, é uma das principais vantagens da técnica (MARTÍNEZ-ZAPATER et al., 2000).

Analisando 38 clones e nove variedades (Carbenet Sauvignon, Chardonnay, Merlot, Pinot Blanc, Pinot Gris, Pinot Noir, Sauvignon Blanc, Schiava Grossa e Traminer), BELLIN et al. (2001) verificaram uma maior eficiência da técnica fAFLP na distinção entre as variedades do que entre os diferentes acessos (espécies), dando ênfase a possibilidades futuras de desenvolvimento de marcadores SCAR (Região Amplificada de uma Seqüência Caracterizada) a partir do fAFLP.

O presente trabalho teve como objetivo a busca de marcas moleculares associadas à ausência de sementes em videira, utilizando as técnicas RAPD e fAFLP.

\section{MATERIAL E MÉTODOS}

Material Vegetal -Folhas jovens de 19 cultivares (Itália, Brasil, Patrícia, Christmas Rose, Niágara Rosada, Isabel, Alphonse Lavallée, Benitaka,
Superior Seedless, Catalunha, Centennial Seedless, Perlette, Thompson Seedless, Vênus, Marroo Seedless, Beauty Seedles, IAC 313, IAC 766, IAC 572) foram coletadas, maceradas em nitrogênio líquido e armazenadas a $-20^{\circ} \mathrm{C}$ até o momento de uso.

Extração de DNA - Para análise RAPD, utilizou-se o método de extração desenvolvido por LODHI et al. (1994), e para análise fAFLP, o método de DOYLE \& DOYLE(1991).

RAPD - Cada reação PCR constou de 50 ng de DNA, tampão de PCR (Invitrogen) $1 \mathrm{X}, \mathrm{MgCl}_{2} 1,5 \mathrm{mM}$, dNTP 0,2mM, 1,0U Taq DNA polimerase (Invitrogen), 3ng $\mu \mathrm{L}^{-1}$ de iniciador, água milli-Q filtrada q.s.p. $20 \mu \mathrm{L}$. Os DNAs foram amplificados utilizando termociclador (PTC-100 Programable Thermal Controler - MJ Research, Inc.) e submetidos a um ciclo de $94^{\circ} \mathrm{C}$ por $1 \mathrm{~min} ; 92^{\circ} \mathrm{C}$ por $1 \mathrm{~min} ; 35^{\circ} \mathrm{C}$ por $1 \mathrm{~min} ; 92^{\circ} \mathrm{C}$ por $1 \mathrm{~min}$; $35^{\circ} \mathrm{C}$ por $1 \mathrm{~min}$; $72^{\circ} \mathrm{C}$ por $2 \mathrm{~min}$; 40 vezes $\left(92^{\circ} \mathrm{C}\right.$ por $1 \mathrm{~min}$; $35^{\circ} \mathrm{C}$ por $1 \mathrm{~min} ; 92^{\circ} \mathrm{C}$ por $1 \mathrm{~min} ; 35^{\circ} \mathrm{C}$ por $1 \mathrm{~min} ; 72^{\circ} \mathrm{C}$ por $2 \mathrm{~min}$ ) e, finalmente, um ciclo de $72^{\circ} \mathrm{C}$ por $5 \mathrm{~min}$. Foram avaliados 213 iniciadores de 10 pares de bases das marcas "Operon" e "The University of British Columbia”. Em cada tubo, contendo $20 \mu \mathrm{L}$ do DNA amplificado, foram adicionados $3 \mu \mathrm{L}$ de tampão de amostra (azul de bromofenol 0,01\%; glicerol 40\%). Desta mistura, $10 \mu \mathrm{L}$ foram colocados nas canaletas de gel de agarose 1,5\% (dissolvida em TEB $1 \mathrm{X}$ - TRIS 89mM, ácido bórico 89mM, EDTA 2,5mM, pH 8,3) e submetidos à eletroforese horizontal no sistema Sunrise (Gibco BRL), em tensão de $100 \mathrm{~V}$ por aproximadamente $90 \mathrm{~min}$. A coloração foi feita usando brometo de etídio na concentração de $5 \mu \mathrm{L} 100 \mathrm{~mL}^{-1}$ de gel, e de $10 \mu \mathrm{L}$ $100 \mathrm{~mL}^{-1}$ no tampão de eletrodo (TEB 1X). A visualização dos resultados das amostras, após a eletroforese, foi realizada em equipamento de fotodocumentação (Gel Doc - 1000 - Bio Rad) e gravada para as análises posteriores.

Extração de DNA para análise f-AFLP - Para a extração de DNA, foi utlizado tecido foliar individualmente de cada amostra. Foi utilizado o método proposto por DOYLE \& DOYLE (1991). Alíquotas das amostras de DNA foram submetidas à eletroforese em gel de agarose $0,8 \%$, onde se aplicaram também alíquotas de DNA de concentrações conhecidas, que serviram de padrão para a quantificação das amostras utilizando-se o software Quantity ONE (Bio Rad).

fAFLP - Empregou-se o protocolo AFLP Plant Mapping. O DNA genômico foi digerido utilizando-se a seguinte reação: 500ng DNA, $1,25 \mu \mathrm{L}$ de tampão React 1 (Invitrogen) (500mM Tris-HCl pH 8,0, $100 \mathrm{mM} \mathrm{MgCl}_{2}$ ), $5 \mathrm{U}$ de Eco RI, $1 \mathrm{U}$ de Mse I, água milliQ qsp $10 \mu \mathrm{L}$. A reação foi incubada por $720 \mathrm{~min}$ a $37^{\circ} \mathrm{C}$ e em 
seguida, as enzimas foram inativadas por $10 \mathrm{~min}$, a $65^{\circ} \mathrm{C}$. Os fragmentos foram ligados a adaptadores (PE Applied Biosystems), utilizando-se de $1 \mu \mathrm{L}$ tampão T4 DNA Ligase (Invitrogen), 0,5 $\mu \mathrm{L}$ T4 DNA ligase, 0,33 $\mu \mathrm{L}$ do adaptador para o corte da Mse I, $0,33 \mu \mathrm{L}$ do adaptador para o corte da Eco RI e 3,67 $\mu \mathrm{L}$ da reação de digestão. A ligação ocorreu por $120 \mathrm{~min}$ a $20^{\circ} \mathrm{C}$ e então foi diluída 8,5X. Procedeu-se à amplificação pré-seletiva dos fragmentos com reações de $20 \mu \mathrm{L}$. Utilizaram-se 3,0 $\mu \mathrm{L}$ do produto da ligação diluído, $15 \mu \mathrm{L}$ de Core Mix (PE Applied Biosystems), 1,0 $\mu \mathrm{L}$ do iniciador para o adaptador Eco RI $(1 \mu \mathrm{M})$ e $1,0 \mu \mathrm{L}$ do iniciador para o adaptador Mse I $(5 \mu \mathrm{M})$. As condições de amplificação consistiram de 30 ciclos de $94^{\circ} \mathrm{C}$ por $30 \mathrm{~s}, 56^{\circ} \mathrm{C}$ por $1 \mathrm{~min}$ e $72^{\circ} \mathrm{C}$ por $1 \mathrm{~min}$. Após verificação da reação pré-seletiva em gel de agarose, os produtos da amplificação préseletiva foram diluídos 10X e serviram de templete para a amplificação seletiva, cuja reação foi semelhante à anterior; entretanto, utilizaram-se iniciadores de mesmas seqüências que os empregados na reação anterior, porém com adição de três bases na extremidade 3' e com marcação fluorescente. A amplificação foi realizada com uma etapa denaturante inicial de $94^{\circ} \mathrm{C}$ por $2 \mathrm{~min}$, seguida de 10 ciclos de $94^{\circ} \mathrm{C}$ por 20s, $66^{\circ}$ (diminuindo um grau por ciclo) por $30 \mathrm{~s} \mathrm{e} 72^{\circ} \mathrm{C}$ por $2 \mathrm{~min}, 20$ ciclos de $94^{\circ} \mathrm{C}$ por $20 \mathrm{~s}, 56^{\circ} \mathrm{C}$ por 30 s e $72^{\circ} \mathrm{C}$ por $2 \mathrm{~min}$ e uma etapa final de $60^{\circ} \mathrm{C}$ por $30 \mathrm{~min}$. As amostras foram eletroforizadas em seqüenciador ABI 377 (Perkin-Elmer) por 3h, e a análise foi conduzida através do software GeneScan 3.1 (Perkin-Elmer) e Genotyper 2.5 (PerkinElmer). Com os perfis fAFLP obtidos para cada planta, montou-se uma tabela binária. As combinações de iniciadores testadas foram: ACC/CTC; ACC/CTT; ACC/ CAT; ACC/CTA; AAG/CTC; ACT/CTC; ACT/CTA; ACT/CTG e AGG/CTT. As matrizes obtidas (RAPD e fAFLP) foram analisadas utilizando o programa Phylip 3.2 (FELSENSTEIN, 1989) para gerar o dendrograma.

\section{RESULTADOS E DISCUSSÃO}

O emprego da técnica RAPD demonstrou uma grande diferença genética entre as cultivares estudadas. Dentre os 213 iniciadores utilizados, apenas 30 proporcionaram eficiência na amplificação de todas as amostras (Tabela 1), gerando um total de 462 bandas. Desse total, 392 bandas eram polimórficas $(80,82 \%)$ e apenas as mais intensas foram analisadas. De um modo geral, os portaenxertos foram os que mais se destacaram em relação à reprodutibilidade, não tendo sido encontrados problemas de amplificação dos porta-enxertos com a maioria dos iniciadores testados, o que também os
Tabela 1 - Relação dos iniciadores selecionados, com suas respectivas seqüências e número de fragmentos polimórficos (NFP) gerados.

\begin{tabular}{|c|c|c|}
\hline Iniciadores & Seqüência 5' - 3' & NFP \\
\hline \multicolumn{3}{|c|}{ Operon } \\
\hline B7 & GGT GAC GCA G & 9 \\
\hline B12 & CCT TGA CGC A & 19 \\
\hline D11 & AGC GCC ATT G & 19 \\
\hline \multicolumn{3}{|c|}{ University of British Columbia - UBC } \\
\hline 301 & CGG TGG CGA A & 11 \\
\hline 302 & CGG CCC ACG T & 21 \\
\hline 303 & GCG GGA ACC C & 13 \\
\hline 304 & AGT CCT CGC C & 20 \\
\hline 309 & ACA TCC TGC G & 20 \\
\hline 310 & GAG CCA GAA G & 16 \\
\hline 311 & GGT AAC CGT A & 3 \\
\hline 312 & ACG GCG TCA C & 9 \\
\hline 313 & ACG GCA GTG G & 13 \\
\hline 317 & CTA GGG GCT G & 24 \\
\hline 318 & CGG AGA GCG A & 18 \\
\hline 319 & GTG GCC GCG C & 13 \\
\hline 324 & ACA GGG AAC G & 15 \\
\hline 331 & GCC TAG TCA C & 20 \\
\hline 333 & GAA TGC GAC G & 16 \\
\hline 335 & TGG ACC ACC C & 16 \\
\hline 336 & GCC ACG GAG A & 19 \\
\hline 338 & CTG TGG CGG T & 18 \\
\hline 341 & CTG GGG CCG T & 18 \\
\hline 342 & GAG ATC CCT C & 7 \\
\hline 344 & TGT TAG GCA C & 16 \\
\hline 383 & GAG GCG CTG C & 16 \\
\hline 441 & CTG CGT TCT T & 18 \\
\hline 442 & CTA CTC GGT T & 14 \\
\hline 443 & TGA TTG CTC G & 23 \\
\hline 482 & CTA TAG GCC G & 11 \\
\hline 485 & AGA ATA GGG C & 16 \\
\hline 490 & AGT CGA CCT T & 14 \\
\hline Total de bandas & & 485 \\
\hline $\begin{array}{l}\text { Total de bandas } \\
\text { polimórficas }\end{array}$ & & 392 \\
\hline
\end{tabular}

diferenciou dos outros grupos (com e sem sementes)

Ao utilizar o iniciador OP - B11 (GTA GAC CCG T), obteve-se uma possível banda característica para uvas sem sementes nas cultivares Brasil e Beauty Seedless; entretanto, não foi possível sua repetibilidade nas demais cultivares em questão. Empregando-se o iniciador UBC 443 (TGA TTG CTC G), observou-se uma banda bastante intensa, presente apenas nas cultivares sem sementes, o que também pode representar uma característica específica de videiras apirenas (Figura 1). De forma contrária, utilizando o iniciador UBC 340, a amplificação só foi 


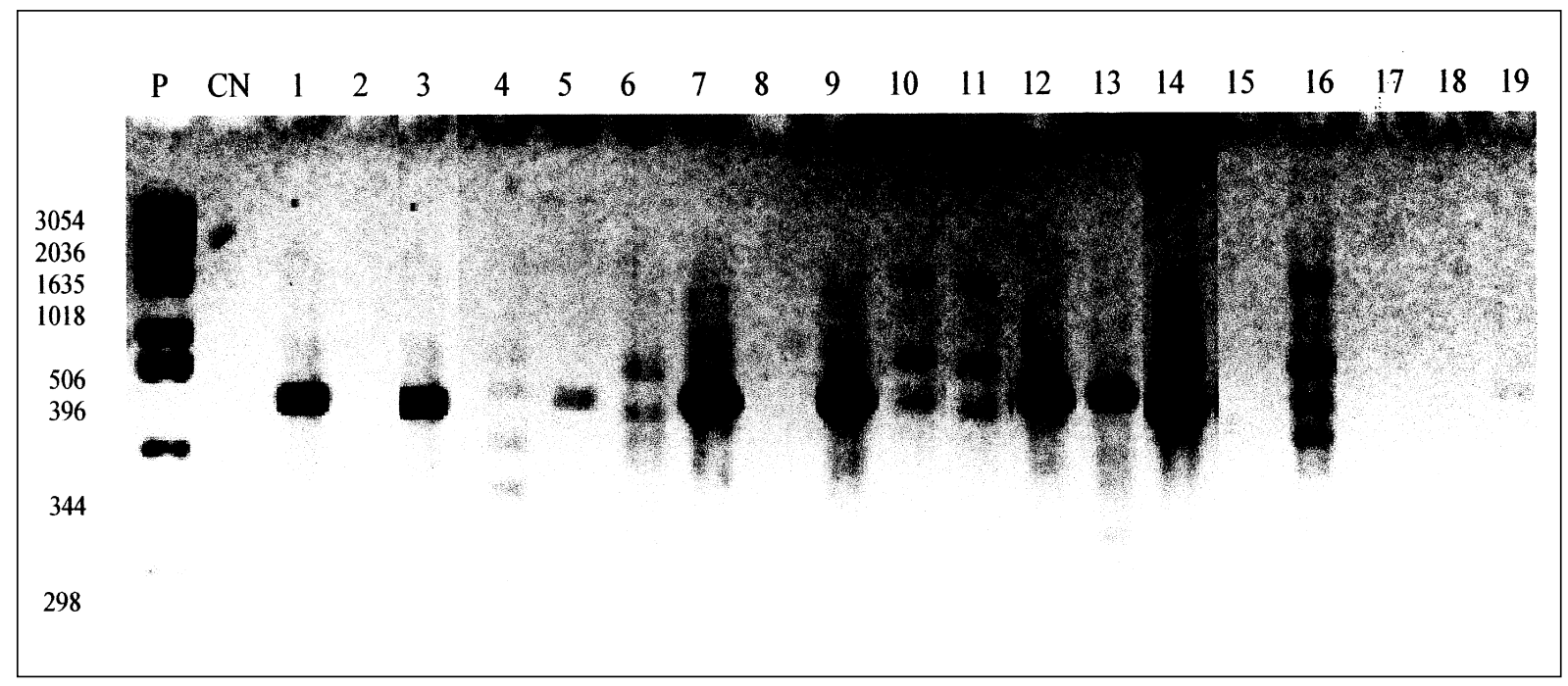

Figura 1 - Padrões de bandeamento utilizando o iniciador UBC - 443, com destaque (setas) para as bandas presentes nas cultivares sem sementes (canaletas 1, 3, 5, 7, 9, 12, 13 e 14). (P) Padrão de peso molecular de 1Kb; (CN) controle negativo.

possível nas cultivares com sementes; porém, sem maiores resoluções de bandas.

O resultado obtido na utilização do iniciador UBC 443 responde claramente ao objetivo deste trabalho, uma vez que a resolução do gel permitiu uma verificação concreta das bandas específicas encontradas nas cultivares sem sementes. Posteriormente será possível o desenvolvimento de marcadores SCAR (Regiões amplificadas de seqüências características) (PARAN \& MICHELMORE, 1993) a partir dessas marcas RAPD encontradas, possibilitando o desenvolvimento de um teste de identificação rápida e precoce de apirenia em videira. Alguns iniciadores proporcionaram grande quantidade de bandas monomórficas, como o UBC 442, as quais estão presentes em todas as amostras. Isso pode ocorrer com freqüência, porque, mesmo sendo cultivares diferentes, pertencem ao mesmo gênero (JESOVSEK, 1995).

A natureza molecular dos fragmentos amplificados utilizando-se iniciadores arbitrários não está completamente elucidada e não se sabe ao certo se cada fragmento no gel pode ser considerado um caráter independente. De fato, tem sido demonstrado que muitos fragmentos RAPDs segregam como herança mendeliana, indicando um único locus por fragmento (REITER et al., 1992; TINKER et al., 1993). Entretanto, há uma alta probabilidade de estes fragmentos amplificados conterem repetitivas seqüências (DEVOS \& GALE, 1992; PARAN \& MICHELMORE, 1993), que podem distorcer a chave taxonômica. A análise de um grande número de fragmentos, pelo uso de vários iniciadores, contribui para diminuir este problema.
Para a realização da análise de similaridade, apenas os iniciadores que amplificaram todas as amostras foram utilizados, construindo-se assim um dendrograma (Figura 2). Analisando-o, pode-se perceber que não foi possível a separação de grupos distintos, exclusivos para uvas com sementes e sem sementes. Na realidade, foram obtidos sete grupos, sendo que três deles são constituídos de uvas com sementes; um, de uvas sem sementes; e um específico com os porta-enxertos utilizados. Acv. Patrícia agregouse ao grupo de uvas sem sementes, formado pelas cultivares Perlette, Thompson Seedless e Beauty Seedless; e a cv. Benitaka, que é uma mutação somática da cv. Itália, agregou-se às cultivares Superior Seedless e Catalunha, ambas sem semente.

Na análise fAFLP, as seis combinações de iniciadores (NED - ACC/CAT; NED - ACC/CTA; NED ACT/CTT; FAM -ACT/CTG; FAM - ACT/CTC e FAM - ACT/CTT) geraram 386 bandas polimórficas. Esse número é superior ao encontrado por SENSI et al. (1996) que, utilizando oito iniciadores, obtiveram 164 bandas, e também superior ao resultado de NARVÁEZ et al. (2000) que, com quatro iniciadores, obtiveram 86 bandas polimórficas.

Utilizando a combinação dos três iniciadores FAM para construção do dendrograma (Figura 3), foi possível a distinção de sete grupos (três de uvas com sementes, três de uvas sem sementes e um grupo com os três porta-enxertos), o que dá a real possibilidade de um grande avanço na identificação de marcas específicas para apirenia e cultivares de videira. Essa representação gráfica permite estimar as relações genéticas entre as cultivares, e verifica-se que a cv. 


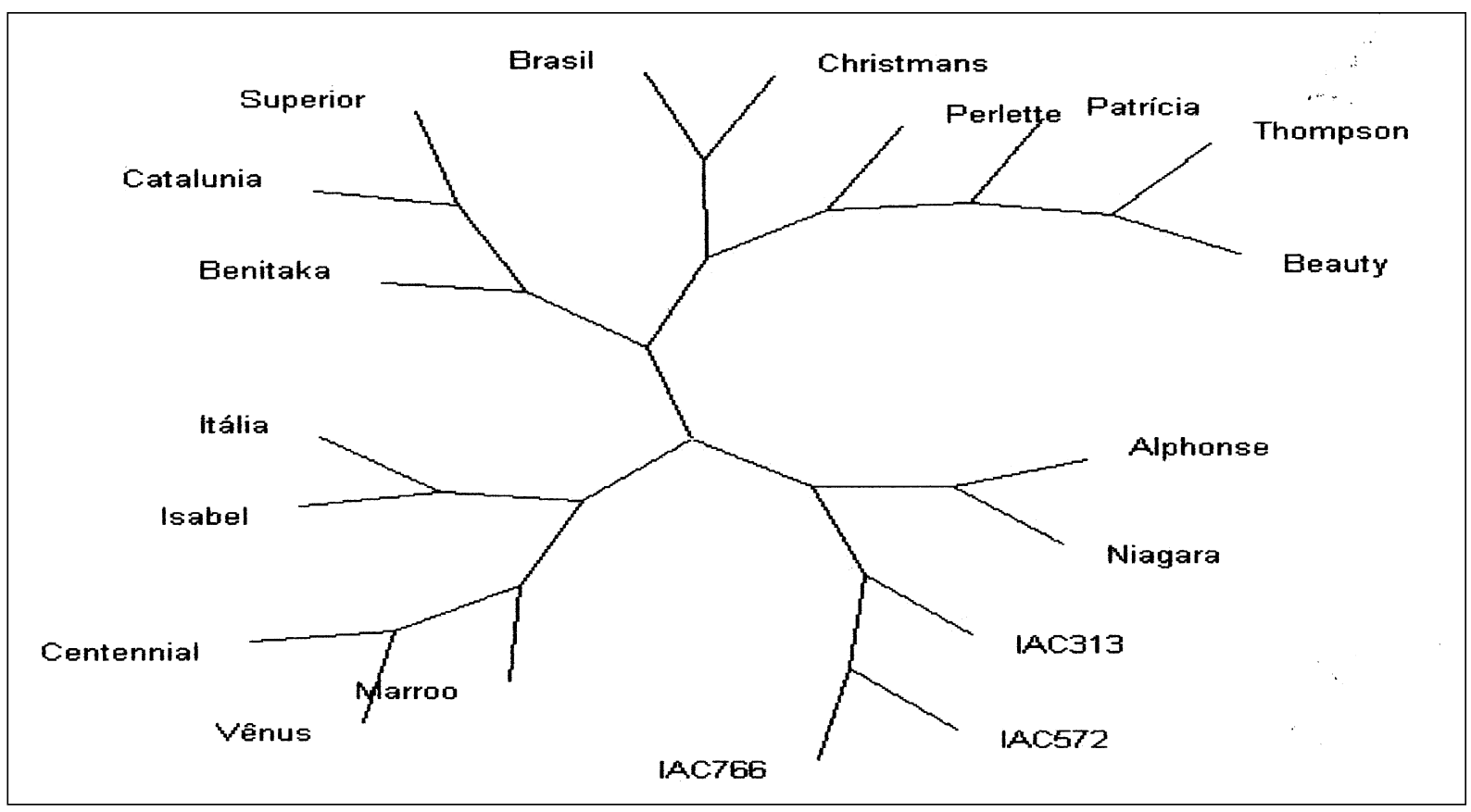

Figura 2 - Dendrograma construído pelo programa Phylip versão 3.2, que relaciona todas as cultivares de Vitis sp. analisadas com os 30 iniciadores selecionados para identificação de marcas moleculares associadas à ausência de sementes em videira.

Vênus (sem semente) agrupou-se às cultivares com sementes (Niágara Rosada e Isabel). Isso pode ser explicado, pelo fato de que, apesar de ser uma cultivar

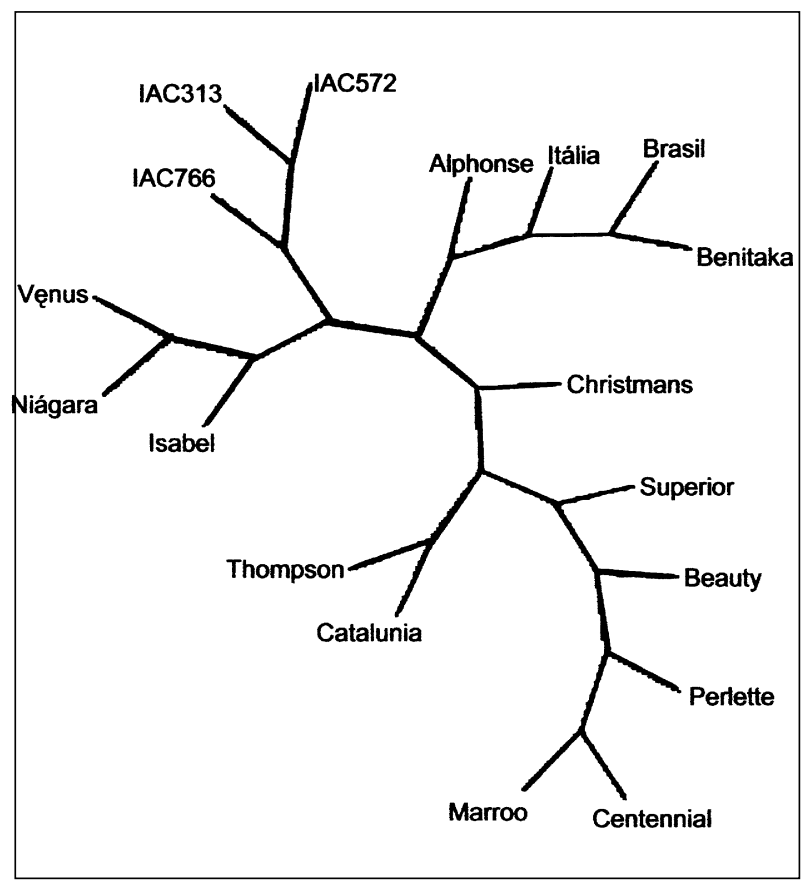

Figura 3 - Dendrograma construído pelo programa Phylip versão 3.2, que relaciona todas as cultivares de Vitis sp. analisadas com os seis iniciadores selecionados para identificação de marcas associadas à ausência de sementes em videira. apirena, pertence ao grupo das uvas americanas, que é o mesmo grupo da 'Niágara Rosada' e a da 'Isabel'.

Também foi possível verificar a proximidade genética entre as cultivares Brasil, Benitaka e Isabel, uma vez que a 'Brasil' é uma mutação da 'Benitaka', que é uma mutação da 'Itália', ambas pertencentes ao grupo de uvas européias (espécie Vitis vinifera). A 'Isabel', apesar de pertencer ao grupo de uvas americanas (espécie Vitis labruscana), é um híbrido natural de videiras americanas e européias.

Além disso, obtiveram-se grupos específicos para os três porta-enxertos e para uvas sem sementes, sendo, sem dúvida, a melhor combinação de iniciadores testada, por ter permitido a visualização da similaridade genética entre as cultivares e agrupamento por tipos (com sementes, sem sementes e portaenxertos).

Conclui-se que, utilizando a técnica RAPD, obteve-se uma marca molecular bastante expressiva com o iniciador UBC 443 (TGA TTG CTC G), presente em todas as cultivares sem sementes e ausente nas demais. Conseqüentemente, será possível o desenvolvimento de marcadores SCAR a partir dessas marcas RAPD encontradas, possibilitando a criação de um teste de identificação rápida e precoce de apirenia em videira. Além disso, foi possível identificar marcadores específicos para várias cultivares, independentemente da presença ou ausência de sementes, visto que, devido a diversas mutações 
existentes no gênero, pode ocorrer dificuldade na definição da identidade de cultivares. Se as diferenças encontradas geneticamente estão ou não relacionadas com diferenças morfológicas identificadas nas cultivares em outros estudos, este trabalho representa um material de grande importância, a começar pela caracterização dos fragmentos polimórficos amplificados em gel. Os dados obtidos por fAFLP também apresentam-se como uma importante ferramenta para estudos futuros, principalmente para a construção de mapa genético de ligação de alta densidade, havendo, entretanto, a necessidade de ser testada uma maior quantidade de combinações de iniciadores, podendo-se iniciar com os já selecionados neste trabalho. Os mapas genéticos de ligação facilitam a localização e identificação de genes de interesse para melhoramento assistido por marcadores e posterior clonagem desses genes.

\section{REFERÊNCIAS}

BELLIN, D. et al. Intravarietal DNA polymorphisms in grapevine (Vitis vinifera L.) polymorphisme intravarietal de L'ADN chez la vigne. Acta Horticulturae, v.546, p.343349, 2001.

DEVOS, K.M.; GALE, M.D. The use of random amplified polymorphic DNA markers in wheat. Theoretical Applied Genetic, v.84, p.567-572, 1992.

DOYLE, J.J.; DOYLE, J.L. Isolation of plant DNA from fresh tissue. Focus, v.1, p.13-15, 1991.

FELSENSTEIN, J.P. Phylogeny inference package (Version 3.2). Clasistics, v.5, p.164-166, 1985.

GALET, A. A practical ampelography: grapevine identification. Ithaca: Lommstock, 1979. 248p.

GRAY, D.; MEREDITH, C. Grape. In: HAMMERSCHLAG, F.; LITZ, R. Biotechnology of perennial fruit crops. Wallingford: CAB International, 1992. p.229-269.
HANCOCK, J.F. Plant evolution and the origin of crop species. Englewood Cliffs: Prentice-Hall, 1992. 297p.

JESOVSEK, G.K. Utilização de marcadores moleculares na caracterização de espécies do gênero Cássia. 1995. 67f. Dissertação (Mestrado em Agronomia) - Curso de Pósgraduação em Melhoramento Vegetal, Universidade Estadual Paulista.

LODHI, M.A. et al. A simple and efficient method for DNA extraction from grapevine cultivars and Vitis species. Plant Molecular Biology Reporter, Dordrecht, v.12, n.1, p.6-13, 1994.

MARÍNEZ-ZAPATER, J.M. et al. AFLPs in genetic identification and genome analysis of grapevine. Acta Horticulturae, v.528, p.105-110, 2000.

NARVÁEZ, C.R. et al. Comparasion of RAPD and AFLP as methods for genetic identification on Vitis based on the analysis of anonymous genomic sequences. Agricultura Técnica, v.60, n.4, p.320-340, 2000.

PARAN, I.; MICHELMORE, R.W. Development of reliable PCR-based markers linked to downy mildew resistence genes in lettuce. Theoretical Applied Genetic, v.85, p.985993, 1993.

REGNER, F. et al. Considerations about the evolution of grapevine and the kole of traminer. Acta Horticulturae, v.528, p.177-179, 2000.

REITER, R.S. et al. Global and local genome mapping in Arabidopsis thaliana by using inbred lines and random amplified polymorphic DNAs. Proceedings Nature Academic Science, v.89, p.1477-1481, 1992.

SCOTT, K.D. et al. AFLP markers distinguishing an early mutant of Flame Seedless grape. Euphytica, v.113, n.3, p.245249, 2000.

STRIEM, M.J. et al. Genomic DNA fingerprinting of Vitis vinifera by the use of multi-loci probes. Vitis, v.29, p.223227, 1990.

TINKER, N.A.et al. Random amplified polymorphic DNA and pedigree relationships in spring barley. Theoretical Apllied Genetic, v.85, p.976-984, 1993. 